\title{
INTERMENSTRUAL PAIN.
}

By R. D. PUREFOY, M.D., F.R.C.S.,

Ex-Master of the Rotunda Hospital.

[Read in the Section of Obstetrics, December 11, 1908.]

ONE of the least common and least understood varieties of pain connected with, and dependent on, ovarian functions is that to which Priestly, in 1872, applied the term "intermenstrual." Medical literature does not abound in records of cases in which this pain has been observed; and even in the records furnished us details are but sparsely given, both as to treatment and its results. In my experience the affection has proved generally rebellious to treatment, and very liable to recurrence. Observers are pretty well agreed that it is an affection of late, rather than of early years, probably most frequently met with between the ages of twentyfive and thirty-five. Its relation to child-bearing deserves notice. Those who suffer from it are in most instances sterile, or, if mothers, have not been pregnant for several years. In some of my cases it occurred for the first time after the conclusion of a pregnancy; in none was it experienced during the very early years of menstrual life.

The majority of those who suffer in this way describe the attack as beginning at a point of time midway between two menstruations; but I have noticed that in a proportion of cases it begins ten or seven days before menstruation. Relief is generally coincident with the establishment of the menstrual flow; and entire cessation of the pain generally ensues for a variable period. In some in- 
stances an observable discharge, either uterine or vaginal, synchronises with the pain; two of $\mathrm{my}$ cases illustrate this fact.

Menstruation in these cases does not follow any invariable type, and is sometimes normal in amount; but in my observation is more generally either scanty or profuse, and attended with pain.

A very interesting question remains--viz., with what lesions of the ovaries or other organs is this affection most frequently associated. On this, as on so many other points connected with our subject, we are compelled to speak somewhat vaguely, as neither from our own expreience nor from that of others has it been found possible to draw reliable conclusions. I have found it associated with (1) healthy uterus and appendages; (2) endometritis; (3) subinvolution; (4) retroversion. We may at this point advantageously contrast some of the many opinions expressed by others on the subject of this communication. lawson Tait alludes to this affection thus:-- Since reading Dr. Priestley's paper, I have seen several cases, but have been unable to refer them to any category." In Bland Sutton and Giles' "Gynæcology" we read:"Causation and pathology of this affection are as vet obscure; it has been attributed to recurring painful ovulation, independent of menstruation. The more probable explanation is that it is due to painful efforts on the part of a diseased tube to expel its contents. In the majority of instances it has been found associated with tubal mischief, and especially with that curious condition known as intermittent hydrosalpinx. It is suggested that the uterine congestion which precedes menstruation causes occlusion of the uterine ostium and accumulation of catarrhal contents in the tube; the distension causes pain. When menstruation occurs the con- 
gestion is relieved and the uterine ostium of the tube becomes patent, and the tube discharges its contents. Pain is then relieved."

The authors may claim some credit for their ingenuity in elaborating such a theory; but it is not in accord with clinical facts, though, as we shall see a little later, Dr. Martin seems inclined to accept this view. When writing of ovarian dysmenorrhœa, the late Dr. Thomas observes:- "One very curious phenomenon which now and then marks these cases is the accurrence of intermenstrual pain. At times this occurs with wonderful regularity on a certain day. In one case in my experience it occurred on the ninth day after menstruation had ceased, in another on the fourteenth, and in a third it commenced one week after the menstrual act and continued for five or six days." Fehling explains intermenstrual pain as a normal ovulation between two menstrual periods. On this point Macnaughton-Jones remarks:- "How common such pain is every gynæcologist is aware, and the relief of this symptom as well as the pain of ordinary menstruation by treatment of the ovaries, or their massage, is explained by the consequent changes of the relative position of the adnexa and uterus."

With every respect for the learned writer, I find myself unable to accept as accurate the statement "that such pain is common," or that the alteration of the relative position of the uterus and the adnexa has the effect attributed to it. Hermann alludes to this condition under the title, "intermediate dysmenorrhoa," and favours the notion that it depends on the regular monthly maturation of an ovum, the process being painful because the outer part of the ovary is thickened, either from fibrous growth or organised inflammatory lymph. For treatment, he 
suggests that we should treat the disease of the ovary on which it depends. Christopher Martin writes:- "The pain is regular in its onset, always fourteen days before the next period; it is violent and occurs in paroxysms, and lasts for three or four days. It is accompanied by a watery discharge from the uterus; in a few cases the discharge is hæmorrhagic, but scanty, so that there is an abortive period in the middle of each interval. On examination, the pelvic organ may be found normal', but there are usually distinct signs of chronic inflammation in the tubes or ovaries. In a considerable number of cases the condition of hydrosalpinx has been found associated with intermenstrual pain, and by most authorities is believed to be the cause thereof."

I have never seen a case in which this pain was "violent. and paroxysmal," though this would be easily understood if it were associated with hydrosalpinx, which, in my exyerience, is by no means common. Intermenstrual pain. is generally, though not always, referred to either ovarian region, and sometimes to the right and left sides alternately. In two cases recently under my care it was felt in the breasts alone.

Brief records of some of my cases are as follow:-

CASE I.-Patient, aged thirty-four, unmarried, rather delicate from childhood; menstruation came on rather late, and has become increasingly painful. At present presents most of the features of well-marked ovarian dysmenorrhœea; severe pain in groins, and tenderness of breasts a few days before the flow appears, attended sometimes with headache and retching. For the past few years severe intermenstrual pain, beginning fourteen days after the first day of preceding illness; no disease of uterus or ovaries discoverable.

CASE II.-Patient, aged thirty-four, healthy aspect, fifteen years married, nine children. About eighteen months after last confinement began to suffer from intermenstrual pain in left side 
extending into groin. Examination disclosed nothing more than slight enlargement of uterus and endometritis; no disease of: appendages was detected. This patient suffered in a marked degree from dyspepsia and constipation, for the relief of which she underwent treatment during some months, together with occasional uterine treatment, and for a time complete relief from the intermenstrual pain was obtained. Amongst other drugs pcrseveringly used were iodide of potassium and bichloride of mercury. In this case the intermenstrual pain is attended by discharge.

CASE III.-Patient, aged thirty-five, three years married. During her first and only pregnancy, which ended eighteen months ago, was in poor health, and her urine was highly albuminous. Uterus somewhat enlarged; os externum small and circular, affording no evidence whatever of parturition having occurred. Some glairy discharge is constantly present; abdominal walls very thick; appendages not distinctly felt. Has suffered much from intermenstrual pain, especially during the last year. Treatment in this case has been followed by much relief, the intermenstrual pain especially having nearly ceased. In my opinion, aspirin contributed to this satisfactory result.

CASE IV.-Paticnt, unmarried, aged twenty-seven; complains. much of failing health, loss of weight and energy, and frequent attacks of nausea, especially at meal-time. Menstruation is painful, and a vaginal examination shows that the uterus is low in pelvis, and retroverted. In tbis case the intermenstrual pain is in the breasts, not in the pelvis. Under treatment, local and constitutional, the dysmenorrhoa and nausea were completely cured, and the mammary distress alleviated.

CASE V.-Patient, aged forty-one, nine years married. Some months before marriage, following exposure to cold, irregular menstruation and frequent sick headaches were a source of much trouble, and about the same time patient began to suffer from. pain and swelling in both breasts, starting a fortnight before each illness.

CASE VI.-Patient, aged thirty-three, single, troubled with frequent micturition and menstruation, discharge returning every two weeks, attended with swelling and tenderness of breasts. Pelvic conditions, vulvitis and vaginitis; uterus retroverted and 
adherent ; much evidence of endometritis. Several days after each menstruation severe crampy pain is experienced in lower belly accompanied by red discharge. Treatment afforded but little relief.

CASE VII.-Patient, aged twenty-nine, four years married, two children. Suffers much pain in belly, discomfort and vomiting between menstruation; the pain begins on the 20th and lasts till the 28 th of each month. Local conditions: laceration and ectropion of cervix, uterine cavity three and a half inches. Treatment brought about a healthy state of the uterus, but very little diminution of the intermenstrual pain.

CASE VIII.-Patient, aged twenty-six, three years married, childless. Chief trouble is headache, beginning one week after, and lasting till one week before, menstruation. Nothing worth noting in the condition of the pelvic organs.

It may be readily understood from the foregoing that treatment must be varied, directed to the removal, if possible, of any ascertained morbid conditions, and, in their absence (and, indeed, in every case), to the improvement of the general health. In a few cases, which have proved not amenable to other measures, the removal of one or both ovaries has been practised, but with results so variable and inconstant that it cannot be advised in future, unless as a last and desperate resource. We should, I think, refrain as much as possible from the exhibition of narcotics, especially opium. Perhaps an exception may be made in favour of Indian hemp, especially if given in pill with quinine. It will be well to bear in mind the varying strength of different samples of this drug, and, in order to avoid the production of sometimes alarming constitutional disturbance, to instruct our patient to take it always shortly after food. Recently I have given aspirin once or twice in the day with encouraging results. Arsenic, too, deserves to be remembered amongst the remedies likely to be of any service. 
In my opinion, intermenstrual pain is dependent on, and caused by, the maturation of a Graafian follicle in an ovary itself in a pathological condition, and generally surrounded by structures which have been implicated in an inflammatory process.

Treatment, to be effectual in giving relief, should be constitutional to improve the general health, and local to relieve, as far as may be done, the associated diseased conditions. 